\title{
Is the Rural-Access-Index (RAI) a Reflection of Rural and Urban Poverty? A Data Analysis
}

\author{
Charles Alba \\ ${ }^{I}$ The Pennsylvania State University, University Park, USAs
}

\section{A R T I C L E I N F O}

Article history:

Received 21 September 2020

Received in revised form 30 September 2020

Accepted 2 October 2020

Available online 1

November 2020

Keywords:

Rural Access Index, Urban

Poverty, Rural Poverty,

Sustainability,

Infrastructure, Rural

Planning, Transport,

Economic Development

\section{A B S T R A C T}

While there are plenty of studies to support that infrastructural developments aimed at enhancing accessibility do reduce both rural and urban poverty, it is not tied to any global indicator. This is concerning for planners and policy analysts, especially those in developing nations, for they do not have a reflective indicator to rely on when attempting to optimize resource allocation towards accessible infrastructure development. Hence, in this paper, we aim to assess if the Rural Access Index (RAI) accurately reflects a nation's rural and urban poverty levels. This is based on the concept that accessibility is key to eradicating poverty. We do so by performing a regression analysis on the RAI against Rural and Urban Poverty. Our analysis determines that the RAI does indeed reflect Rural and (the square-root of) Urban poverty in relation to infrastructural development. Thus, the RAI could aid national planners and authorities in roadway infrastructural planning. It could thus be used as a specialized indicator towards the optimal allocation of resources for infrastructural developmental purposes aimed at eradicating rural and urban poverty through rural accessibility.

Copyright (C) Universitas Pendidikan Ganesha. All rights reserved.

\section{Introduction}

Throughout history, economic indicators have been utilized to reflect specific societal dimensions and its relations to one's Standard of Living and Quality of Life (Bílková, 2020; Feldmeyer et al., 2020). This is because socio-economic indicators deepen the understanding or the state of prevailing issues. This allows experts or authorities to gain insights into tackling a societal challenge with the aim of solving social and economic issues (Feldmeyer et al., 2020). Thus, a range of individuals ranging from planners to elected officials use socio-economic indicators as statistical figures towards interest tools for policy analysis (Mazziotta, 2019). Henceforth, indicators are vital in pursuit of optimizable solutions - the concept of minimizing trade-offs to achieve the best possible outcome (Unterhalter, 2019). Thus, such could only be achieved if the indicators effectively assess or aid a crucially targeted problem (Janoušková et al., 2018). Based on its reflection of the targeted problem, policy analyst and relevant authorities could mathematically gage the distribution of relevant resources to mitigate the persisting issue (Bondarenko et al., 2019).

The goal of optimization comes solely due to limitation of resources with desires for unlimited solutions towards tackling broader issues. While applicable across all economies, such is particularly pertinent to that of developing countries, for their availability of limited funds (Tierney \& Boodoosingh, 2020) translates towards the greater need to prioritize successful development projects aimed at solving persisting issues (Baffoe, 2019). Thus, the minimization of trade-offs is crucial in the process of ensuring "combinatorial optimization" of funds when performing the special and highly strategic role (Hosseinzadeh et al., 2020) of channeling resources towards successful avenues. This promises the best possible outcome, while minimizing the expense borne towards other channels in its denial of such funds (Moyer \& Bohl, 2019). 
This mandates authorities and planners in evaluating the amount of resources that should be invested into roadway infrastructure, at a national and local level. Having a comparative indicator would allow these authorities to know if more needs to be invested into roadway infrastructure in the continuous efforts to alleviate urban and rural poverty or if enough has been invested into roadway infrastructure and resources should be focused or diverted elsewhere to combat poverty. This is especially pertinent to developing nations, which possesses the arduous task of combating higher rates of rural and urban poverty with limited resources or lower capital. Therefore, knowing the optimal amount of resources needed to boost roadway infrastructure in poverty reduction, comparative to other nations, is crucial.

This application towards infrastructure accessibility and poverty, both in rural and urban areas, is certainly no exception to the minimization of trade-offs. For the longest time, poverty has remained an urgent issue plaguing many individuals across nations. While poverty levels have converged following the conclusion of the United Nations Development goals, it continues remained centrally urgent, in modern times for it has been found that significant variation in poverty reduction performance across countries has disproportionately affected developing countries (Asadullah \& Savoia, 2018; Stein et al., 2019). This can be attributed by the lack of ability of states to administer optimal changes required to witness structural characteristics that would ensue the rapid reduction of poverty (Asadullah \& Savoia, 2018). Investing in roadway infrastructure would give individuals in remote or poverty-ridden areas quicker and more convenient access to opportunistic areas, ranging from accessibility to transportation for crop exports, to the ability for youngsters to attend school.

At a Rural Level, investing in roadway infrastructure in Rural areas reduces the cost of intermediate goods (Srinivasu \& Srinivasa Rao, 2013). Furthermore, through the externality effect, rural economies could now enjoy higher human capital returns due to improved immediate access to education, good quality health and higher efficiency of human capital due to lower marginal depreciation of capital. Furthermore, less accessible areas disincentivizes participation in economic and social activities due to reduced services and social networks (Pot et al., 2020). Such lack of engagement with out-of-home social activity could have further ramifications on one's psychological well-being (De Vos, 2013, 2018; Delbosc \& Currie, 2011; Friman et al., 2017), backed by strong correlations between transport poverty and mobility and activity participation patterns (Panteia, 2019; Stanley et al., 2011).

Lack of accessibility in rural areas may spill over towards Urban poverty. Individuals may choose to reside in rural areas and commute to more opportunistic urban areas for a myriad of reasons ranging from inability to afford urban housing to wanting to reduce themselves to the health risks of urbanization (Parry et al., 2018). Hence, commuting from rural areas to opportunistic areas "may be relatively long" and "may be very time-consuming", thus making them "time poor" (Seetanah \& Ramessur., 2009). Furthermore, long commutes as a result of poor roadway infrastructure could reduce the urban poor's "productivity, thus adding an "energy-poverty" dimension to their deprivation (Seetanah \& Ramessur., 2009). Furthermore, the lack of accessibility to rural areas could affect entrepreneurship in urban areas (Wu \& Si, 2018), where inaccessibility to imported raw goods from rural areas would drive up production costs. Enterprises would now have to either earn potentially reduced profit margins or raise the price of goods to protect profit margins. Therefore, with the recognition that roadway infrastructure is essential to the alleviation of poverty at both an Urban and Rural level, it remains important that authorities have the ability to estimate the amount of resources that should go towards roadway infrastructure in relation to accessibility.

While there remains plenty of infrastructural indicators or metrics published by reputable sources, none of them come remotely close towards the reflection of both Urban and Rural poverty. While taking the length or size of roadway in the country may seem like a simple measure towards roadway infrastructure, it could potentially present problems due to its failure to account for various factors like geographical terrain or density. "Rural population living in areas where elevation is below 5 meters $(\%$ of total population)" may also seem like an appropriate indicator, but it could present various potential discrepancies considering that it ultimately reflects the overall geographical terrain of a nation. Furthermore, with the advancements of engineering and technology, "accessible infrastructure on terrain above 5 meters" could easily be uncommonly mitigated even amongst developing nations (Bajwa, 2018; Kawasaki et al., 2020; Sternberg et al., 2017), in a cost-efficient manner (Kumar et al., 2017). Hence, the Rural Access Index, to be elaborated later, remains imperative towards a nations Rural or Urban poverty, in relation to roadway infrastructure or infrastructural accessibility.

What remains startling is that despite the fact that plentiful of empirical and normative studies have supported roadway infrastructure accessibility in its relation to Urban and Rural poverty alleviation - which would be discussed later - little to no research has been conducted with any concern to the Rural Access Index (RAI). 
Hence, in this article, we would discuss linkages between accessibility of roadway infrastructure and its relation to Urban and Rural poverty based on existing literature. Therefore, we would briefly introduce the Rural Access Index before performing the necessary data analysis to determine if it is reflective of rural and urban poverty to conclude if it should be used as an indicator towards poverty eradication in relation to roadway infrastructure.

In short, the Rural Access Index (RAI) represents "proportion of the rural population who live within $2 \mathrm{~km}$ of an all-season road" (Limi, 2019; Love \& Klapper, 2003). It was originally developed by the World Bank in 2006 and is a Sustainable Development Goals indicator (Irigoyen, 2007). Hence, normatively speaking, if a nation has a high RAI, it demonstrates that the country has a well-distributed and large amounts of roadway infrastructure. Thus, authorities and planners may want to divert its limited resources to other areas of infrastructure to alleviate urban or rural poverty. On the other hand, if an impoverished nation has a low RAI, it demonstrates that the country has a poorly distributed and lowvolume roadway infrastructural network. Thus, one should invest more in roadway infrastructure to eradicate urban or rural poverty. The RAI thus gives an insightful assessment into a nations current roadway infrastructure development and could thus be potentially relied on as an indicator in reflecting Urban and Rural Poverty.

\section{Methods}

The Rural Access Index was retrieved from the World Bank Data Catalog. As mentioned earlier, the Rural Access Index (RAI) represents proportion of the rural population who live within $2 \mathrm{~km}$ of an allseason road. It is collected using spatial data. The original methodology combines three sets of geospatial data: where people live, the spatial distribution of the road network, and road quality. In 2017, a new methodology utilizing spatial techniques and data collected using innovative technologies was been implemented and suggested. These innovative technologies could include high-resolution population distribution data and Digitized road alignment data which consider road conditions. However, it is worth noting that the new methodology has been used nationally in the data collection of only 24 countries. This gives us a rather small sample size, which could get even smaller should the Urban and Rural Poverty data be unavailable for the respective nation. As a result, we shall stick with the original Methodology, which provides us with a more comprehensive list of nations. The dataset of the original Methodology also includes a 'Region' variable which represents the geo-political region that was classified by RAI methodology Department within the World Bank.

The Rural and Urban Poverty data was also retrieved from the World Bank Data Catalog. Rural Poverty Rate is defined as the headcount ratio which the percentage of the rural population living below the national poverty lines. Similarly, the Urban Poverty Rate is defined as the headcount ratio is the percentage of the urban population living below the national poverty lines. We shall use the data of both the Rural and Urban poverty based on the nations respective Reference Year provided by the World Bank Data Catalog.

As mentioned earlier, this study aims to find if the RAI could reflect Rural and Urban poverty and aid national planners and authorities in roadway infrastructural planning. Therefore, we would have to create two models: one with the RAI against Rural Poverty and one with the RAI against Urban poverty. Based on our results, the RAI helps rural and/or poverty in determining if it is an appropriate indicator towards infrastructural Development. In this data analysis, we shall propose a model and test for assumptions towards our proposed model.

Proposed model for the RAI against the Rural poverty model is as follows: (Rural Poverty) $=B_{0}+B_{1}$ (Rural Access Index $)$

Where independent $\varepsilon_{i} \sim N\left(\mu, \sigma^{2}\right)$ and $E\left(y_{i}\right)=B \cdot x_{i}$ with $y=$ (Rural Poverty) and $x=$ (Rural Access Index) of referenced nation $i$. These were concluded based on the testing of assumptions with relevant plots.

With the failure to meet the assumptions of Normality and equal variance, we shall modify our model to meet the assumptions, with the transformation of the square-root as the response variable Urban Poverty Rate.

Thus, the new transformed model will give us the following: $\sqrt{(\text { Urban Poverty) }}=B_{0}+B_{1}$ (Rural Access Index)

Where independent $\varepsilon_{i} \sim N\left(\mu, \sigma^{2}\right)$ and $E\left(y_{i}\right)=B \cdot x_{i}$ with $y=\sqrt{(\text { Urban Poverty) }}$ and $x=$ (Rural Access Index) of referenced nation $i$. These were concluded based on the testing of assumptions with relevant plots. 


\section{Results and Discussions}

As reiterated from earlier, we aim to find if the Rural Access Index (RAI) could reflect Rural and Urban poverty and aid national planners and authorities in roadway infrastructural planning. This would thus give us two models, analyzed in the Methods which would yield the following results.

Table 1. This would thus give us two models

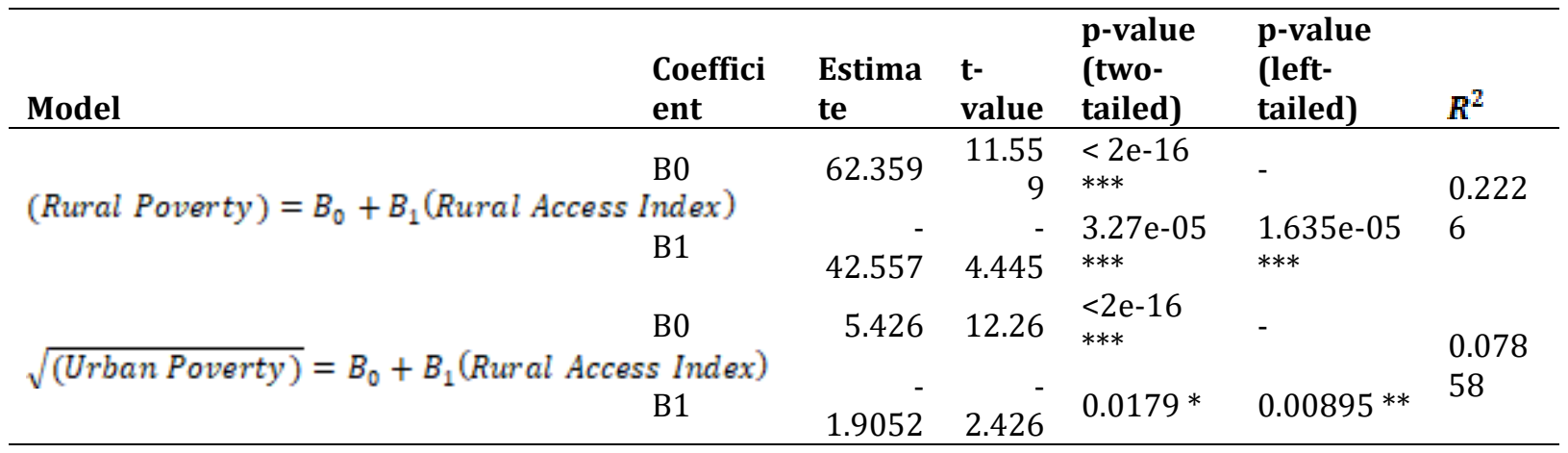

\section{Rural Model}

To interpret the results in context, if a country's entire rural population has no one living within 2 $\mathrm{km}$ of an all-season road (ie no rural community is accessible), the country's expected rural poverty rate would be $62.359 \%$. For every additional percent ( 0.01 in Rural Index) of the rural population who live within $2 \mathrm{~km}$ of an all-season road, the country's Rural poverty rate is expected to decrease by $0.42557 \%$. If the country has everyone living within $2 \mathrm{~km}$ of an all-season road, (ie RAI=1) the predicted rural poverty rate would be $19.80176 \%$. These numerical figures suggest the model is appropriate for they all fall within the $[0,100]$ possible percentage range for rural poverty rates.

At threshold $\alpha=0.01$, since $p$-value $<\alpha$, we have strong evidence to conclude that a higher Accessibility to Rural Areas (Rural Access Index) leads to lower Rural Poverty Rates.

\section{Urban Model (Transformed)}

To interpret the results in context, if a country's entire rural population has no one living within 2 $\mathrm{km}$ of an all-season road, the country's expected poverty rate would be $29.44 \%$. For every additional percent ( 0.01 in Rural Index) of the rural population who live within $2 \mathrm{~km}$ of an all-season road, the country's square-foot Urban poverty rate is expected to decrease by $0.01905 \%$. If the country has everyone living within $2 \mathrm{~km}$ of an all-season road, the predicted urban poverty rate would be $12.39552 \%$. These numerical figures suggest the model is appropriate for they all fall within the $[0,100]$ possible percentage limit for urban poverty rates.

At threshold $\alpha=0.01$, since $p$-value $<\alpha$, we have strong evidence to conclude that a higher Accessibility to Rural Areas (Rural Access Index) leads to lower Urban Poverty Rates based on our transformed model.

\section{Discussion}

Our results support numerous findings which show that infrastructure does relate to both rural and urban poverty. A variety of studies, both empirical and normative, have suggested a state's accessible infrastructural development does reflect its rural poverty levels, at both a local (Bucheli et al., 2018; Sewell et al., 2019), national level (Aggarwal, 2018; Maryati et al., 2020; Nakamura et al., 2019) and international level (Giampiccoli \& Saayman, 2017). The same could be said with regards to urban poverty due to its spillover effects (Beard, 2019; Singh \& Deewan, 2019; Teschner et al., 2020), although less studies have been performed on such. This is due to a myriad of interconnected reasons which has been reviewed earlier above in the "Why is Roadway Infrastructural Accessibility Important?" section.

However, it is worth noting that this study does not aim to confirm an already much known proven economical fact - that Rural accessibility does reduce rural and urban poverty. Rather this paper aims to determine if the Rural Access Index (RAI) is reflective of a nations rural and urban poverty with regards to infrastructural development.

Therefore, such a finding is important, because, while there are plenty of studies to support the mere fact that infrastructural developments aimed at enhancing accessibility do reduce both rural and 
urban poverty, it is not tied to any global indicator made universally made available. Thus, while authorities and policy makers are aware that they have to boost infrastructural development, they do not know the state of the nation's infrastructure in relation to accessibility. Thus, they do not know how much funds should be allocated to this, leading to wasteful funds and suboptimal allocation of resources, particularly in developing countries where funds are limited.

Now that we have established that a specific quantified indicator - the Rural Access Index (RAI) does indeed reflect Rural and Urban poverty, and the extent of such, this could significantly aid both elected and appointed officials in the distribution of limited funds for overall development. Normatively speaking, if a nation does possess a low RAI, compared to nations of similar development status, perhaps more resources have to be distributed to infrastructural development in inaccessible areas. On the other hand, if the RAI remains high, compared to nations of similar development status, perhaps more of the limited resources should be allocated to other areas of development, such as building more infrastructure to decongest cities, having better healthcare facilities and on literacy programs, all of which have the same target of reducing rural and urban poverty.

What makes the RAI and our study particularly unique in relation to its reflection to both Rural and Urban poverty is the fact that instead of broadly targeting a state's infrastructural development status, it targets a specific element of roadway infrastructure - that of its accessibility to rural areas. There are many indicators which planners and policy makers do depend on for infrastructural growth (Adshead et al., 2019; Ameen \& Mourshed, 2019). However, the term infrastructure, or even its subset of roadway infrastructure, is simply too broad and it encompasses a massive number of subfields and aspects (Lawhon et al., 2018). Therefore, officials could have a rough gage on how much should be allocated to infrastructural modernization, but beyond that, they do not know specifically where these funds should be allocated too. But our findings could significantly aid all officials, elected or appointed, local or national, towards specifically planning how much resources should be channelled towards a specific aspect of development, infrastructure in relation to accessibility. Henceforth, now they would not only know how to optimize their limited funds but guarantee useful spending by spending on a specific element of infrastructure - roadway accessibility to rural areas - to ultimately create a ripple effect of opportunities for both rural and urban residents. This could thus alleviate individuals from both rural and urban poverty due to the creation of massive economic opportunities, as elaborated earlier.

\section{Conclusion}

Our results clearly demonstrate that the Rural Access Index (RAI) is reflective of Rural and Urban poverty and its relation to roadway infrastructure. Therefore, it is suggested the RAI should be regarded as a core indicator to gage the country's advancement level in terms of their roadway infrastructure, relative to other nations. Thus, the RAI could clearly serve as an appropriate indicator in aiding national planners and authorities of Rural and Urban poverty alleviation.

Henceforth, the RAI gives an insightful assessment into a nation's current roadway infrastructure development in relation to Urban and Rural Poverty. Thus, authorities and planners could use the RAI as an indicator towards the optimization of infrastructural developmental resources for poverty eradication.

\section{References}

Adshead, D., Thacker, S., Fuldauer, L. I., \& Hall, J. W. (2019). Delivering on the Sustainable Development Goals through long-term infrastructure planning. Global Environmental Change, 59. https://doi.org/10.1016/j.gloenvcha.2019.101975

Aggarwal, S. (2018). Do rural roads create pathways out of poverty? Evidence from India. Journal of Development Economics, 133, 375-395. https://doi.org/10.1016/j.jdeveco.2018.01.004

Ameen, R. F. M., \& Mourshed, M. (2019). Urban sustainability assessment framework development: The ranking and weighting of sustainability indicators using analytic hierarchy process. Sustainable Cities and Society, 44, 356-366. https://doi.org/10.1016/j.scs.2018.10.020

Asadullah, M. N., \& Savoia, A. (2018). Poverty reduction during 1990-2013: Did millennium development goals adoption and state capacity matter? World Development, 105, 70-82. https://doi.org/10.1016/j.worlddev.2017.12.010

Baffoe, G. (2019). Exploring the utility of Analytic Hierarchy Process (AHP) in ranking livelihood activities for effective and sustainable rural development interventions in developing countries. Evaluation and Program Planning, 72, 197-204. https://doi.org/10.1016/j.evalprogplan.2018.10.017 
Bajwa, A. S. (2018). Emerging Technologies \& Their Adoption Across Us Dot's: A Pursuit To Optimize Performance In Highway Infrastructure Project Delivery. University of Kansas.

Beard, V. A. (2019). Community-based planning, collective action and the challenges of confronting urban poverty in Southeast Asia. Environment and Urbanization, 31(2), 575-596. https://doi.org/10.1177/0956247818804453

Bílková, D. (2020). Wage Level as One of the Most Important Indicators of the Quantitative Aspect of the Standard of Living of the Population and Selected Indicators of Economic Maturity in OECD Member Countries. Engineering Economics, 31(3), 334-344. https://doi.org/10.5755/j01.ee.31.3.23441

Bondarenko, Y., Azarnova, T., Kashirina, I., \& Vasilchikova, E. (2019). Model for the Development of an Energy Enterprise. Energy Management of Municipal Transportation Facilities and Transport, 566577. https://link.springer.com/chapter/10.1007/978-3-030-57450-5_49

Bucheli, J. R., Bohara, A. K., \& Villa, K. (2018). Paths to development? Rural roads and multidimensional poverty in the hills and plains of Nepal. Journal of International Development, 30(3), 430-456. https://doi.org/10.1002/jid.3327

De Vos, J. (2013). Travel and subjective well-being: a focus on findings, methods and future research needs. Transport Reviews, 33(4), 421-442. https://doi.org/10.1080/01441647.2013.815665

De Vos, J. (2018). Towards happy and healthy travellers: A research agenda. Journal of Transport \& Health, 11, 80-85. https://doi.org/10.1016/j.jth.2018.10.009

Delbosc, A., \& Currie, G. (2011). The spatial context of transport disadvantage, social exclusion and wellbeing. Journal of Transport Geography, 19(6), 1130-1137. https://doi.org/10.1016/j.jtrangeo.2011.04.005

Feldmeyer, D., Meisch, C., Sauter, H., \& Birkmann, J. (2020). Using OpenStreetMap Data and Machine Learning to Generate Socio-Economic Indicators. ISPRS International Journal of Geo-Information, 9(9), 498. https://doi.org/10.3390/ijgi9090498

Friman, M., Gärling, T., Ettema, D., \& Olsson, L. E. (2017). How does travel affect emotional well-being and life satisfaction? Transportation Research Part A: Policy and Practice, 106, 170-180. https://doi.org/10.1016/j.tra.2017.09.024

Giampiccoli, A., \& Saayman, M. (2017). Community-based tourism, responsible tourism, and infrastructure development and poverty. African Journal of Hospitality, Tourism and Leisure, 6(2), 1-26. http://www.ajhtl.com/uploads/7/1/6/3/7163688/article_19_vol_6_2_2017.pdf

Hosseinzadeh, F., Paryzad, B., Pour, N. S., \& Najafi, E. (2020). Fuzzy combinatorial optimization in fourdimensional tradeoff problem of cost-time-quality-risk in one dimension and in the second dimension of risk context in ambiguous mode. Engineering Computations, 37(6), 1967-1991. https://doi.org/10.1108/EC-03-2019-0094

Irigoyen, J. (2007). Rural access and poverty alleviation. Transport, Water and ICT The World Bank. https://sustainabledevelopment.un.org/content/documents/23610411RuralAccess.pdf

Janoušková, S., Hák, T., \& Moldan, B. (2018). Global SDGs assessments: Helping or confusing indicators? Sustainability, 10(5), 1540. https://doi.org/10.3390/su10051540

Kawasaki, T., Kobayashi, M., \& Shibasaki, R. (2020). Southern Africa: Overcoming corridor and border challenges for landlocked countries. Global Logistics Network Modelling and Policy, 301-302. https://doi.org/10.1016/B978-0-12-814060-4.00015-0

Kumar, P., Lewis, P., \& McCarthy, T. (2017). The potential of active contour models in extracting road edges from mobile laser scanning data. Infrastructures, 2(3). https://doi.org/10.3390/su9040531

Lawhon, M., Nilsson, D., Silver, J., Ernstson, H., \& Lwasa, S. (2018). Thinking through heterogeneous infrastructure Configurations. Urban https://doi.org/10.1177/0042098017720149

Limi, A. (2019). Measuring Rural Access: Update 2017/18. World Bank. http://documents.worldbank.org/curated/en/543621569435525309/pdf/World-MeasuringRural-Access-Update-2017-18.pdf. 
Love, I., \& Klapper, L. F. (2003). Corporate Governance, Investor protection, and Performance in Emerging Markets. https://doi.org/10.1596/1813-9450-2818

Maryati, S., Firman, T., Humaira, S., \& Febriani, Y. T. (2020). Benefit Distribution of Community-Based Infrastructure: Agricultural Roads in Indonesia. Sustainability, 12(5). https://doi.org/10.3390/su12052085

Mazziotta, M. (2019). Socio-Economic Indicators for Measuring the Well-Being of Italian Municipalities. Scienze Regionali, 18, 633-650. https://doi.org/10.14650/94670

Moyer, J. D., \& Bohl, D. K. (2019). Alternative pathways to human development: Assessing trade-offs and synergies in achieving the Sustainable Development Goals. Futures, 105, 199-210. https://doi.org/10.1016/j.futures.2018.10.007

Nakamura, S., Bundervoet, T., \& Nuru, M. (2019). Rural roads, poverty, and resilience: evidence from Ethiopia. The World Bank, 19. https://doi.org/10.1596/1813-9450-8800

Panteia. (2019). Sociale inclusie en vervoersarmoede in de provincie Zuid-Holland. Panteia, Zoetermeer.

Parry, L., Davies, G., Almeida, O., Frausin, G., de Moraés, A., Rivero, S., \& Torres, P. (2018). No Title. Annals of the American Association of Geographers, 108(1), 125-143. https://doi.org/10.1080/24694452.2017.1325726

Pot, F. J., Koster, S., Tillema, T., \& Jorritsma, P. (2020). Linking experienced barriers during daily travel and transport poverty in peripheral rural areas: the case of Zeeland, the Netherlands. European Journal of Transport and Infrastructure Research, 20(3), 29-46. https://doi.org/10.18757/ejtir.2020.20.3.4076

Seetanah, B., \& Ramessur., S. (2009). Does Infrastructure Alleviates Poverty In Developing Countries? International Journal of Applied Econometrics and Quantitative Studies, 6(2).

Sewell, S. J., Desai, S. A., Mutsaa, E., \& Lottering, R. T. (2019). A comparative study of community perceptions regarding the role of roads as a poverty alleviation strategy in rural areas. Journal of Rural Studies, 71,73-84. https://doi.org/10.1016/j.jrurstud.2019.09.001

Singh, V., \& Deewan, S. (2019). Impact of Corporate Social Responsibility in Sustainable Agriculture \& Rural Infrastructure. Productivity, 59(4), 394-412. https://doi.org/10.32381/PROD.2019.59.04.9

Srinivasu, B., \& Srinivasa Rao, P. (2013). Infrastructure Development and Economic Growth: Prospects and Perspective. Journal of Business Management \& Social Sciences Research (JBM\&SSR), 2(1).

Stanley, J. K., Hensher, D. A., Stanley, J. R., \& Vella-Brodrick, D. (2011). Mobility, social exclusion and wellbeing: exploring the links. Transportation Research Part A, 45(8), 789-801. https://doi.org/10.1016/j.tra.2011.06.007

Stein, S., Andreotti, V. D. O., \& Suša, R. (2019). 'Beyond 2015', within the modern/colonial global imaginary? Global development and higher education. Critical Studies in Education, 60(3), 281-301. https://doi.org/10.1080/17508487.2016.1247737

Sternberg, T., Ahearn, A., \& McConnell, F. (2017). Central Asian 'characteristics' on China's new Silk Road: The role of landscape and the politics of infrastructure. Land, 6(3), 55. https://doi.org/10.3390/land6030055

Teschner, N., Sinea, A., Vornicu, A., Abu-Hamed, T., \& Negev, M. (2020). Extreme energy poverty in the urban peripheries of Romania and Israel: Policy, planning and infrastructure. Energy Research \& Social Science, 66. https: //doi.org/10.1016/j.erss.2020.101502

Tierney, A., \& Boodoosingh, R. (2020). Challenges to NGOs' ability to bid for funding due to the repatriation of volunteers: The case of Samoa. World Development, 136, 105-113. https://doi.org/10.1016/j.worlddev.2020.105113

Unterhalter, E. (2019). The many meanings of quality education: politics of targets and indicators in SDG 4. Global Policy, 10, 39-51. https://doi.org/10.1111/1758-5899.12591

Wu, J., \& Si, S. (2018). Poverty reduction through entrepreneurship: Incentives, social networks, and sustainability. Asian Business \& Management, 17(4), 243-259. https://doi.org/10.1057/s41291018-0039-5 